\title{
Influence of particle size, additive ratio and chemical structure of zinc borate on mechanical properties of poly(vinyl chloride)
}

\author{
Yeliz İpek ${ }^{1,2, *}$ \\ ${ }^{1}$ Munzur University, Vocational School of Tunceli, Department of Chemistry and Chemical Process Technologies, Tunceli, 62000, \\ Turkey \\ ${ }^{2}$ Munzur University, Rare Earth Elements Research and Application Center, Tunceli, 62000, Turkey
}

\section{ARTICLE INFO}

Article history:

Received July 3, 2021

Accepted October 29, 2021

Available online December 31, 2021

Research Article

DOI: $10.30728 /$ boron.961843

Keywords:

Composite

Flame retardant

PVC

Smoke suppressant

Zinc borate

\begin{abstract}
Zinc borate (ZB) is a flame retardant and smoke supressant compound of boron. It is widely used to achieve flame resistant polymer composites. Poly(Vinyl Chloride) (PVC) is one of the commercially important polymers that is mostly used for cable insulating, windows, doors, pipes, floorings and toys etc.. On the other hand, PVC releases toxic gases during fire as decomposition products. Zinc borate addition is thought to be a solution for this problem. However, this solution leads a new problem. Zinc borate effects the mechanical properties of the PVC. In the present study, to optimize the contribution of zinc borate, with different formulations $\left(2 \mathrm{ZnO} \cdot 3 \mathrm{~B}_{2} \mathrm{O}_{3} \cdot 3.5 \mathrm{H}_{2} \mathrm{O}\right.$ and $\left.4 \mathrm{ZnO} \cdot \mathrm{B}_{2} \mathrm{O}_{3} \cdot \mathrm{H}_{2} \mathrm{O}\right)$, with different additive ratios ( $1 \%$ and $5 \%$ by weight) and different particle sizes (nano-sized and micro-sized) were added to the PVC structure and the mechanical and thermomechanical properties of each composite were investigated. Mechanical properties of composites were determined by tensile test, impact test, hardness test while thermomechanical behaviours were detected with dynamic mechanical analysis (DMA). In the perspective of mechanical strength of PVC-ZB composite, additive ratio of ZB was more effective than particle size and chemical formulation of ZB. The additive ratio more than $5 \%$ by weight can negatively affect the mechanical strength and quality of the PVC-ZB composite.
\end{abstract}

\section{Introduction}

Development of technology increased the use of energy cables. In electrical installations, cables made of PVC are widely used. The cables, that surround the world like a network, are suitable for fire progression. Toxic gases are released during burning of the PVC insulated cables as decomposition products $[1,2,3]$. In fire conditions, extinguishing and rescue operations are difficult because of the smoke. Many people die because of toxic gas emissions, not because of burning.

PVC polymer is not suitable for processing after it was produced. For this reason, PVC is shaped after addition of heat stabilizer, filler, flame retardant, colorant and plasticizers. Plasticizers constitute the most important group of additives in PVC. PVC composites containing plasticizers are defined as soft PVC (flexible PVC, plasticized PVC, pPVC) [4]. PVC, that do not consist plasticizers, is often referred as rigid PVC (unplasticized PVC or uPVC) [5]. PVC is one of the most used amorphous plastics. Rigid PVC has two usage areas as pipes and window profiles. Soft or flexible PVC is mostly used in cable industry, flooring, toys etc.. When the PVC is heated, especially PVC with low heat stability, it adheres to metal surfaces. PVC is weatherproof, long lasting, easy to processing, and insulates electricity.

Zinc borate is a multi functional material for being both flame retardant and smoke suppressant $[6,7]$. It is widely used for polymeric composites as non-halogenated flame retardant, smoke suppressant, antibacterial agent [8, 9] and char promoter [10, 11]. Zinc borate with a formulation of $2 \mathrm{ZnO} \cdot 3 \mathrm{~B}_{2} \mathrm{O}_{3} \cdot 3.5 \mathrm{H}_{2} \mathrm{O}$ is used as flame retardant, smoke supressant for various polymers [12]. During combustion of a polymeric composite, boron oxide compound of zinc borate melts and physically wrapps around polymeric chains like an isolating blanket [13]. Zinc borate releases its crystal water, cools down the polymer surface and reduces the concentration of flammable gases during combustion of PVC. Zinc borate reacts with hydrogen chloride during thermal degradation of PVC. Thus, toxic gas is transformed into a less harmfull material as zinc chloride $[14,15]$.

Recently, researchers focused on halogen free flame retardants $[16,17,18,19]$. Zinc borate is one of the most preferred halogen free flame retardants. $\mathrm{Pi}$ et al. [20], produced PVC composites using high-ener- 
gy mechanical ball milling. They doped zinc borate to prepare $\mathrm{PVC} / \mathrm{ZB}$ composite and doped aluminum trihydrate to achieve PVC/ZB-ATH composite. Zhang et al. [21] synthesized zinc borate $\left(4 \mathrm{ZnO} \cdot \mathrm{B}_{2} \mathrm{O}_{3} \cdot \mathrm{H}_{2} \mathrm{O}\right) /$ reduced graphene oxide (RGO) material and doped it into poly(Vinyl Chloride) (PVC) as a flame retardant and smoke suppressant. They reported that the flame retardancy and smoke suppression properties of flexible PVC were improved. However zinc borate doping may affect the mechanical properties of PVC. The mechanical behaviors of polymers consisting of large molecules are highly depend on their molecular structures. The conditions under which the materials can be used define their usage areas and the life of the materials depend on their thermal and mechanical properties. Thus, investigation on the affect of the ZB dop on mechanical properties of PVC-ZB composite is important. Demirel et al. [22] reported a decrease in the mechanical properties of flame retardant doped polyester composite due to poor interfacial interaction between zinc borate and polyester. Erdoğdu et al. [23], investigated the synergistic effect of zinc borate and zinc phosphate on thermal resistance of PVC. They exhibited that the synergistic effect was higher than when the materials were doped alone. The synergistic usage of zinc borate also improved the mechanical properties of composites. Jian et al. [24] stated that zinc borate@ZIF-8 (ZB@ZIF-8) hybrid nanorods enhanced the physical-mechanical property of epoxy thermosets.

The mechanical and thermomechanical properties of PVC-ZB composites in the aspect of doping with different formulations $\left(2 \mathrm{ZnO} \cdot 3 \mathrm{~B}_{2} \mathrm{O}_{3} \cdot 3.5 \mathrm{H}_{2} \mathrm{O}\right.$ and $\left.4 \mathrm{ZnO} \cdot \mathrm{B}_{2} \mathrm{O}_{3} \cdot \mathrm{H}_{2} \mathrm{O}\right)$, with different additive ratios $(1 \%$ and $5 \%$ by weight) and different particle sizes (nanosized and micro-sized) were investigated in this study. After mechanical tests had been applied, scanning electron microscopy (SEM) images of the composites were also taken to see the powder distrubution in the polymer structure. Tensile test, impact test, hardness test and dynamic mechanical analysis (DMA) were applied to the prepared composites. The novelty of this study is particularly based on thermal and mechanical properties of the PVC-ZB composite that was exhibited with DMA studies.

\section{Materials and Methods}

\subsection{Preparation of PVC-ZB composites}

Zinc borate powder was synthesized with the procedures of Mergen et al. [25]. Chemical precipitation method with ammonia was employed to synthesize zinc borate powder with a formula of $2 \mathrm{ZnO} \cdot 3 \mathrm{~B}_{2} \mathrm{O}_{3} \cdot 3.5 \mathrm{H}_{2} \mathrm{O}$. Zinc nitrate hegzahydrate $\left(\mathrm{Zn}\left(\mathrm{NO}_{3}\right)_{2} \cdot 6 \mathrm{H}_{2} \mathrm{O}\right.$; Merck, $>99 \%)$ and borax pentahydrate $\left(\mathrm{Na}_{2} \mathrm{~B}_{4} \mathrm{O}_{7} \cdot 5 \mathrm{H}_{2} \mathrm{O}\right.$; supplied from Eti Mine Works, 99.9\%) were used as reagents. After stoichiometric amounts of $\mathrm{Na}_{2} \mathrm{~B}_{4} \mathrm{O}_{7} \cdot 5 \mathrm{H}_{2} \mathrm{O}$ and $\mathrm{Zn}\left(\mathrm{NO}_{3}\right)_{2} \cdot 6 \mathrm{H}_{2} \mathrm{O}$ had been dissolved in distilled water separately with a molar ratio of $1: 8$, respectively, they were mixed in batch reactor to synthesize micro- sized zinc borate powder or in aqueous ammonia solution $\left(\mathrm{NH}_{3}\right.$, Merck, 25\%) to synthesize nano-sized zinc borate powder at $45^{\circ} \mathrm{C}$. A white powder with a formula of $2 \mathrm{ZnO} \cdot 3 \mathrm{~B}_{2} \mathrm{O}_{3} \cdot 3.5 \mathrm{H}_{2} \mathrm{O}$ was precipitated, washed and filtered with distilled water for three times. The filtered cake was dried in an oven at $70^{\circ} \mathrm{C}$. The nano-sized zinc borate with a formula of $4 \mathrm{ZnO} \cdot \mathrm{B}_{2} \mathrm{O}_{3} \cdot \mathrm{H}_{2} \mathrm{O}$ (fire brake) was crystallized with fast evaporation of ammonia after $2 \mathrm{ZnO} \cdot 3 \mathrm{~B}_{2} \mathrm{O}_{3} \cdot 3.5 \mathrm{H}_{2} \mathrm{O}$ powder had been dissolved in water-ammonia solvent. $2 \mathrm{ZnO} \cdot 3 \mathrm{~B}_{2} \mathrm{O}_{3} \cdot 3.5 \mathrm{H}_{2} \mathrm{O}$ solution was boiled to evaporate all of the ammonia solvent and precipitate the powder in $4 \mathrm{ZnO} \cdot \mathrm{B}_{2} \mathrm{O}_{3} \cdot \mathrm{H}_{2} \mathrm{O}$ form. The resultant nano-sized zinc borate powder, which had a chemical formula of $4 \mathrm{ZnO} \cdot \mathrm{B}_{2} \mathrm{O}_{3} \cdot \mathrm{H}_{2} \mathrm{O}$, was washed with distilled water and dried in an oven at $70^{\circ} \mathrm{C}$.

The synthesized nano/micro-sized zinc borate particles were doped into PVC to obtain a flame retardant composite. The mean particle size of nano-sized zinc borate powder was $150 \mathrm{~nm}$ and the average particle size of micro-sized zinc borate powder was $10 \mu \mathrm{m}$. As reported in other studies on PVC-ZB composites, the concentration of flame retardant changed in the range of $1 \%$ to $5 \%[25,26,27]$. Thus, in this study, $10 \mathrm{~g}$ and $50 \mathrm{~g}$ of $2 \mathrm{ZnO} \cdot 3 \mathrm{~B}_{2} \mathrm{O}_{3} \cdot 3.5 \mathrm{H}_{2} \mathrm{O}$ and $4 \mathrm{ZnO} \cdot \mathrm{B}_{2} \mathrm{O}_{3} \cdot \mathrm{H}_{2} \mathrm{O}$ powder were added to $1 \mathrm{~kg}$ of PVC powder in order to obtain $1 \%$ and $5 \%$ by weight zinc borate containing composites, respectively. The mixtures were first subjected to a very intense mixing process. Prior to plastic injection process, the PVC-ZB composites were mixed using a mechanical mixer (Diosna W240) for 30 minutes. They were then loaded into a twin screw $\left(180-190^{\circ} \mathrm{C}\right)$ [27] plastic injection device and mixed at a stirring speed of $50 \mathrm{rpm}$ [28]. The composite pressed into the mold was cooled and removed from the mold.

The appearances of the injection molds are given in Figure 1.

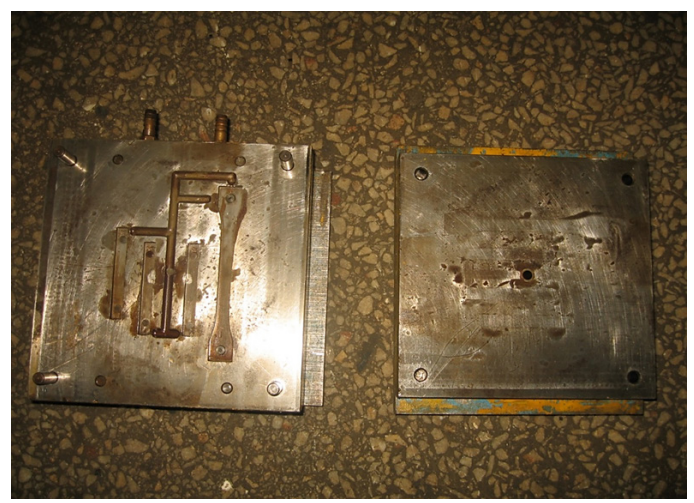

Figure 1. Injection molds which were used for PVC-ZB composite preparation.

The samples were produced in dimensions of $150 \times 10 \times 4 \mathrm{~mm}^{3}$ and $80 \times 9 \times 4 \mathrm{~mm}^{3}$ for tensile test, impact test and dynamic mechanical analysis, respectively (Figure 2).

Detailed sample contents of the produced composites were given in Table 1. 


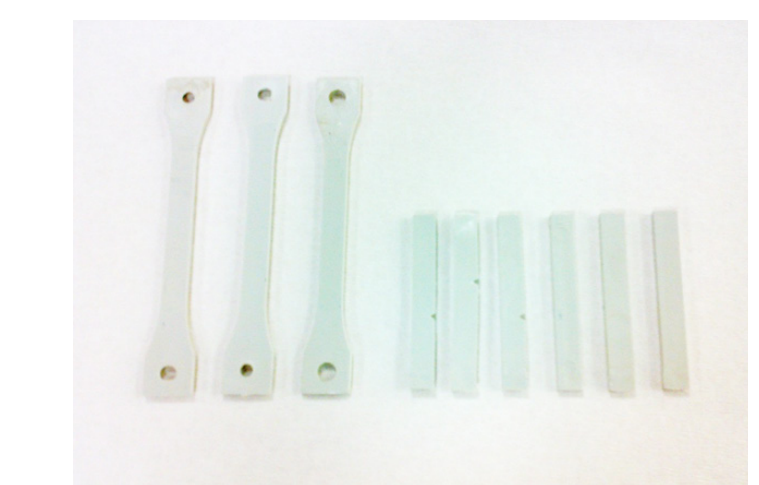

Figure 2. Produced PVC-ZB composites with injection molding technique.

\subsection{Thermal and Mechanical Characterization of PVC-ZB composites}

Tensile test (Zwick Universal Tensile Testing Machine Z010, according to ISO 37), impact test (Zwick Impact, ASTM D4495), hardness test (Zwick, Shore D) was performed for 5 pieces of samples, and dynamic mechanic analysis (Perkin Elmer, DMA 8000) between $30-180^{\circ} \mathrm{C}$ (in $1 \mathrm{~Hz}$ oscillation and $5^{\circ} \mathrm{C} / \mathrm{min}$ heating rate conditions) were applied on PVC and PVC-ZB composites prepared with different zinc borate formulations $\left(2 \mathrm{ZnO} \cdot 3 \mathrm{~B}_{2} \mathrm{O}_{3} \cdot 3.5 \mathrm{H}_{2} \mathrm{O}\right.$ and $\left.4 \mathrm{ZnO} \cdot \mathrm{B}_{2} \mathrm{O}_{3} \cdot \mathrm{H}_{2} \mathrm{O}\right)$, different ratios ( $1 \%$ and $5 \%$ by weight), and different particle sizes (nano- sized and micro-sized particles). Stressstrain $\%$ values of polymers were determined with tensile test. Stress is defined as the force that applied to per unit area of a polymer which causes the polymer to elongate or change shape, while strain is defined as the change in shape with the effect of applied stress and is usually expressed as a change percentage of original form. Impact test defines the capability of a polymer or a composite to withstand an applied load with absorbing the energy and the results were expressed in unit of $\mathrm{J} / \mathrm{m}^{2}$. The impact energy, which should be suddenly applied to a $1 \mathrm{~m}^{2}$ surface to fracture the material, is called impact strength. Also the hardness test was applied for investigatement of zinc borate doping effect on the resistance of PVC against plastic deformations. DMA works by applying a vibratory force to the material and records the temperature-dependent visco-elastic properties that occur in the sample. The applied oscillating force determines the modulus of elasticity and damping. Tan $\delta$ is the ratio of the lost component to the stored component. When tan $\delta$ vs. temperature data are plotted according to temperature, the glass transition temperature is observed as a peak. All of these characterization techniques are useful and very important to know the behaviors of polymer or composite material under special conditions and to control their processes.

\section{Results and Discussion}

\subsection{Tensile Test}

Tensile strength is the ability of a material to resist a force that tends to pull it apart [29]. Tensile strength test results of PVC-ZB composites are given in Figure 3. Tensile test yield points were measured as $35 \mathrm{MPa}$ for PVC, $35 \mathrm{MPa}$ for PVC/nZB2335-1, $33 \mathrm{MPa}$ for PVC/ mZB2335-1 and $36 \mathrm{MPa}$ for PVC/nZB2335-5 sample. The tensile strengths of PVC and PVC-ZB composites with zinc borate additive are given in Table 2 .

The tensile strength of the PVC slightly decreased after addition of zinc borate. The highest decrease ratio was achieved with $5 \%(\mathrm{w} / \mathrm{w})$ addition of mZB2335. Fang et al. [14], inspected the effect of zinc borate doping $(6 \%$ by weight) on the mechanical properties of wood flourPVC composite (WF-PVC). They indicated that the tensile strength of the composite decreased after $19 \%$ $(\mathrm{w} / \mathrm{w})$ zinc borate addition and this result was attributed to the poor interface compatibility between ZB and WFPVC composite.

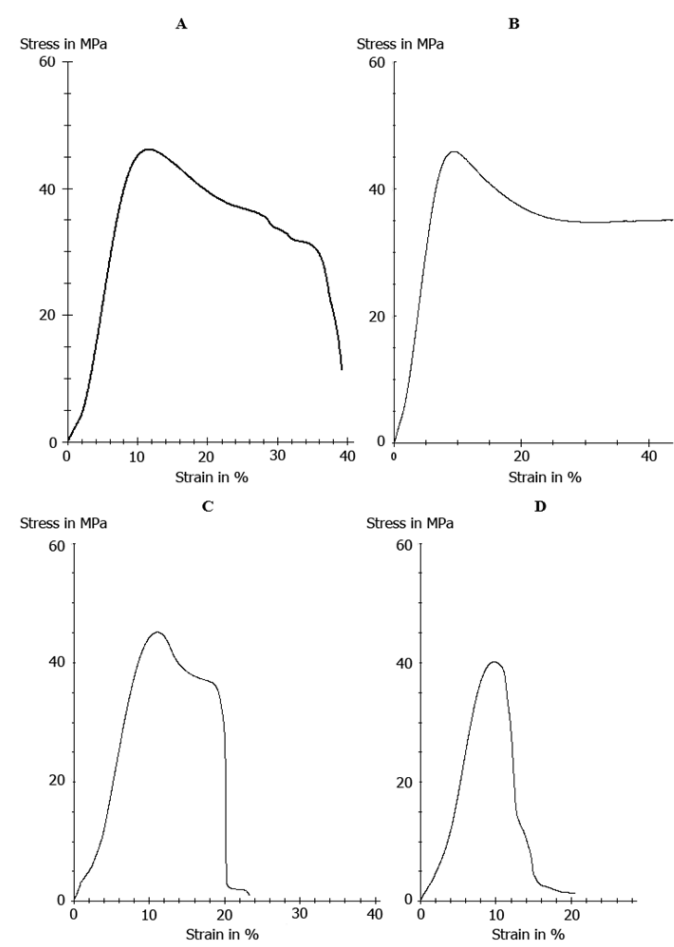

Figure 3. Stress-strain test results of PVC and PVC-ZB composites: A) PVC, B) PVC/nZB2335-1, C) PVC/mZB2335-1, D) PVC/ nZB2335-5.

Table 1. Sample contents of prepared PVC-ZB composites.

\begin{tabular}{ll}
\hline Sample Number & Sample Content \\
\hline PVC/nZB2335-1 & Nano zinc borate $\left(2 \mathrm{ZnO} \cdot 3 \mathrm{~B}_{2} \mathrm{O}_{3} \cdot 3.5 \mathrm{H}_{2} \mathrm{O}\right)$ doped PVC composite, $1 \%(\mathrm{w} / \mathrm{w})$ \\
PVC/mZB2335-1 & Micro-sized zinc borate $\left(2 \mathrm{ZnO}_{3} \cdot 3 \mathrm{~B}_{2} \mathrm{O}_{3} \cdot 3.5 \mathrm{H}_{2} \mathrm{O}\right)$ doped PVC composite, $1 \%(\mathrm{w} / \mathrm{w})$ \\
PVC/nZB2335-5 & Nano zinc borate $\left(2 \mathrm{ZnO} \cdot 3 \mathrm{~B}_{2} \mathrm{O}_{3} \cdot 3.5 \mathrm{H}_{2} \mathrm{O}\right)$ doped PVC composite, $5 \%(\mathrm{w} / \mathrm{w})$ \\
$\mathrm{PVC} / \mathrm{mZB2335-5}$ & Micro-sized zinc borate $\left(2 \mathrm{ZnO} \cdot 3 \mathrm{~B}_{2} \mathrm{O}_{3} \cdot 3.5 \mathrm{H}_{2} \mathrm{O}\right)$ doped PVC composite, $5 \%(\mathrm{w} / \mathrm{w})$ \\
PVC/nZB411-1 & Nano zinc borate $\left(4 \mathrm{ZnO} \cdot \mathrm{B}_{2} \mathrm{O}_{3} \cdot \mathrm{H}_{2} \mathrm{O}\right)$ doped PVC composite, $1 \%(\mathrm{w} / \mathrm{w})$ \\
PVC/nZB411-5 & Nano zinc borate $\left(4 \mathrm{ZnO} \cdot \mathrm{B}_{2} \mathrm{O}_{3} \cdot \mathrm{H}_{2} \mathrm{O}\right)$ doped PVC composite, $5 \%(\mathrm{w} / \mathrm{w})$ \\
\hline
\end{tabular}


Table 2. The tensile strength of PVC and zinc borate doped PVC composites.

\begin{tabular}{lc}
\multicolumn{1}{c}{ Sample } & Tensile Strength (MPa) \\
\hline PVC & $47.016 \pm 0.691$ \\
PVC/nZB2335-1 & $46.080 \pm 0.180$ \\
PVC/mZB2335-1 & $45.630 \pm 0.724$ \\
PVC/nZB2335-5 & $43.150 \pm 0.790$ \\
PVC/mZB2335-5 & $40.268 \pm 1.010$ \\
PVC/nZB411-1 & $46.446 \pm 0.394$ \\
PVC/nZB411-5 & $43.522 \pm 0.431$ \\
\hline
\end{tabular}

The tensile strengths of zinc borate doped PVC composites are lower than that of PVC sample. However, it may be said that the addition of nano zinc borate did not lead a significant decrease in the tensile strength of PVC. While the tensile strength of PVC without zinc borate additive was $47 \mathrm{MPa}$, the tensile strength of PVC doped with nano-sized $2 \mathrm{ZnO} \cdot 3 \mathrm{~B}_{2} \mathrm{O}_{3} \cdot 3.5 \mathrm{H}_{2} \mathrm{O}$ was $46.08 \mathrm{MPa}$ and that of $1 \%$ nano-sized $4 \mathrm{ZnO} \cdot \mathrm{B}_{2} \mathrm{O}_{3} \cdot \mathrm{H}_{2} \mathrm{O}$ doped PVC was $46.4 \mathrm{MPa}$. Thus, it was seen that $1 \%$ (w/w) nano zinc borate additive did not significantly affect the tensile strength of PVC. The addition of $1 \%$ micro-sized $2 \mathrm{ZnO} \cdot 3 \mathrm{~B}_{2} \mathrm{O}_{3} \cdot 3.5 \mathrm{H}_{2} \mathrm{O}$ reduced the tensile strength of PVC to $45.6 \mathrm{MPa}$. When zinc borate additive ratio was increased to $5 \%$, the tensile strength decrease was more pronounced for both nano and micro-sized zinc borate. $2 \mathrm{ZnO} \cdot 3 \mathrm{~B}_{2} \mathrm{O}_{3} \cdot 3.5 \mathrm{H}_{2} \mathrm{O}$ and $4 \mathrm{ZnO} \cdot \mathrm{B}_{2} \mathrm{O}_{3} \cdot \mathrm{H}_{2} \mathrm{O}$ additive decreased the tensile strength of PVC to $43.15 \mathrm{MPa}$ and $43.5 \mathrm{MPa}$, respectively. The same additive ratio $(5 \%)$ of micro-sized $2 \mathrm{ZnO} \cdot 3 \mathrm{~B}_{2} \mathrm{O}_{3} \cdot 3.5 \mathrm{H}_{2} \mathrm{O}$ affected the tensile strength of PVC and decreased it to $40.2 \mathrm{MPa}$. These results showed that micro-sized zinc borate additive affected the tensile strength of PVC composite in the negative way. However, while this decrease was slight with the addition of nano-sized zinc borate, the addition of micro-sized zinc borate resulted in more decrease of tensile strength. The tensile strength of PVC composite decreased as the zinc borate additive ratio was increased. The decrease in the tensile strength of PVC means a decrease in its resistance to mechanical effects and this is an undesirable situation. Increasing the zinc borate additive ratio may increase the flame resistance of PVC-based products while it decreases the mechanical strength quality.

Scanning electron microscopy images of PVC composites and PVC polymer after the tensile strength test are exhibited in Figure 4. The nano-zinc borate particles were observed to be agglomerated and dispersed homogenously in the polymer. This provided an uniform composite stucture. However, in Figure 4(B) it seems that the nano-sized particles were agglomerated and formation of ZB agglomerates lead formation of weak zones in composite structure [30, 31]. Since these zones caused a decrease in tensile strength of the composites, it can be inferred that additive ratio and tensile strength are inversely proportional.

\subsection{Impact Test}

The impact strength of PVC and PVC-ZB composites
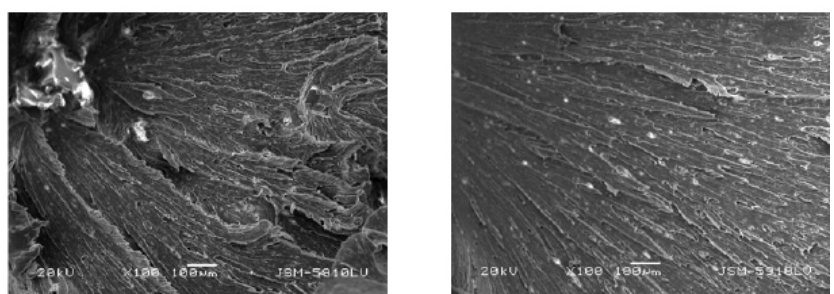

Figure 4. SEM images of A) PVC and B) PVC/nZB2335-1 composite.

are given in Table 3. The impact resistance of PVC was determined to be decreasing with zinc borate addition. While the effect of $1 \%$ by weight of nano-sized zinc borate additive on impact strength of PVC composite was negligible, there was significant decrease in impact strength when the ratio of the zinc borate doping was increased to $5 \%$ as expected. However, the effect of the addition of micro-sized zinc borate on impact resistance was more unfavorable. When microsized zinc borate was added at $5 \%$ weight ratio, the impact strength decreased from $13 \mathrm{~kJ} / \mathrm{m}^{2}$ to $6.8 \mathrm{~kJ} / \mathrm{m}^{2}$.

Table 3. The impact strength of PVC and PVC-ZB composites.

\begin{tabular}{lc}
\hline \multicolumn{1}{c}{ Sample } & Impact Strength $\left(\mathbf{k J} / \mathbf{m}^{2}\right)$ \\
\hline PVC & $13.38 \pm 2.38$ \\
PVC/nZB2335-1 & $12.4 \pm 1.68$ \\
PVC/mZB2335-1 & $11.66 \pm 1.36$ \\
PVC/nZB2335-5 & $7.9 \pm 1.23$ \\
PVC/mZB2335-5 & $6.8 \pm 1.19$ \\
PVC/nZB411-1 & $12.2 \pm 1.04$ \\
PVC/nZB411-5 & $9.65 \pm 2.27$ \\
\hline
\end{tabular}

Scanning electron microscope images of PVC and PVC-ZB composite after impact test are illustrated in Figure 5. Mixing process was applied for half an hour, before the PVC-ZB composite was loaded into the extruder. SEM photographs obtained after the impact strength test of the composite showed that the mixing process time was sufficient and the particles were homogeneously distributed in the polymer structure. However, it was observed that there was a significant decrease in the impact strength of composites containing 5\% ZB additive which can be attributed to agglomeration of particles [30, 31].

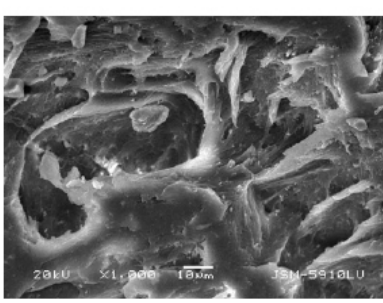

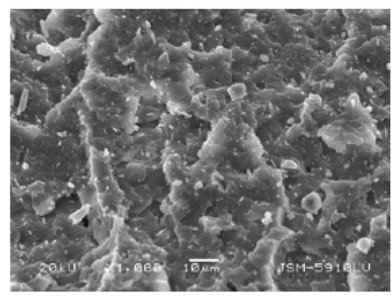

Figure 5. SEM images of A) PVC and B) PVC/nZB2335-1 composite after impact test.

\subsection{Hardness Test}

Hardness test results of PVC and PVC-ZB composites were very close to each other. The hardness values of 
the samples were not affected by zinc borate additive ratio and particle size. Hardness values for all samples ranged between 69-71 Shore $D$ as listed in Table 4 . The hardness value of composites prepared with micro-sized zinc borate particles were slightly lower than the composites containing nano-sized zinc borate. The increase of free volume formed by micro-sized particles were more than the free volume formed by nano-sized ZB powder. Thus, the increase in free volume lead a decrease in hardness of the composite. However, it can be said that both micro and nano-sized particles have the same effect on hardness of the PVC-ZB composite. Yerleşen and Taşdemir [32], studied on the effect of zinc oxide and zinc borate on mechanical properties of high density polyethylene (HDPE). They detected that zinc borate addition to HDPE did not change the hardness value of the polymer up to $5 \%$ doping ratio and the hardness value of the composite increased when the doping ratio was $10-15 \%$ by weight.

Table 4. Hardness of PVC and PVC-ZB composites.

\begin{tabular}{lc}
\hline \multicolumn{1}{c}{ Sample } & Hardness (Shore D) \\
\hline PVC & $70 \pm 1.0$ \\
PVC/nZB2335-1 & $70 \pm 0.5$ \\
PVC/mZB2335-1 & $69 \pm 1.0$ \\
PVC/nZB2335-5 & $71 \pm 1.0$ \\
PVC/mZB2335-5 & $70 \pm 2.0$ \\
\hline
\end{tabular}

\subsection{Dynamic Mechanical Analysis}

The viscoelastic properties of the polymeric materials is measured by using a dynamic mechanical analyzer (DMA). The mechanical properties of polymers vary greatly in the temperatures at glassy transition temperature region $(\mathrm{Tg})$. Glassy transition can be assumed as the most important mechanical characteristic of a polymer. When the results of dynamic mechanical analysis of the PVC sample in the range of $30-180^{\circ} \mathrm{C}$ were examined, the detected modulus value was zero around $100^{\circ} \mathrm{C}$ (Figure 6). Tg value of PVC was detected as $102^{\circ} \mathrm{C}$ according to tan $\delta$ peak. On the other hand, this value was detected to be $82^{\circ} \mathrm{C}$ in terms of modulus.

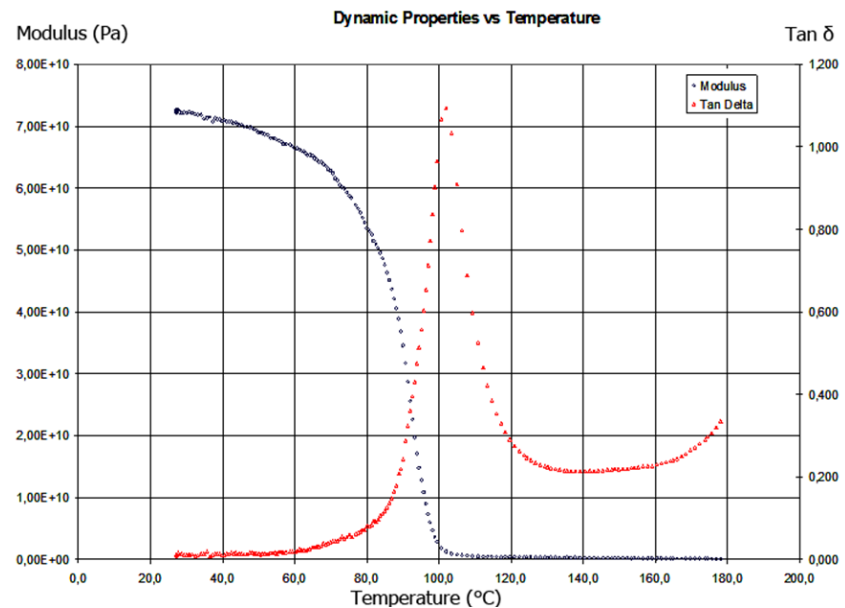

Figure 6. Modulus and dissipation factor (tan delta) graph of PVC between $30-180^{\circ} \mathrm{C}$ temperatures.
When the modulus curves and tan $\delta$ curves were examined, approximately similar behaviors were observed for each PVC-ZB composite sample. Tg values of the PVC/nZB2335-5 composite were detected as $80^{\circ} \mathrm{C}$ and $100^{\circ} \mathrm{C}$ according to modulus curve and tan $\delta$ curve, respectively. In this case, it can be concluded that the zinc borate additive with $5 \%$ ratio lead a slight decrease of glass transition temperature. The starting modulus value of the PVC/nZB2335-5 composite was $10 \times 10^{10} \mathrm{~Pa}$ (Figure 7). This value was found to be higher than that of pure PVC which had a modulus value of $7 \times 10^{6} \mathrm{~Pa}$ at $30^{\circ} \mathrm{C}$ temperature.

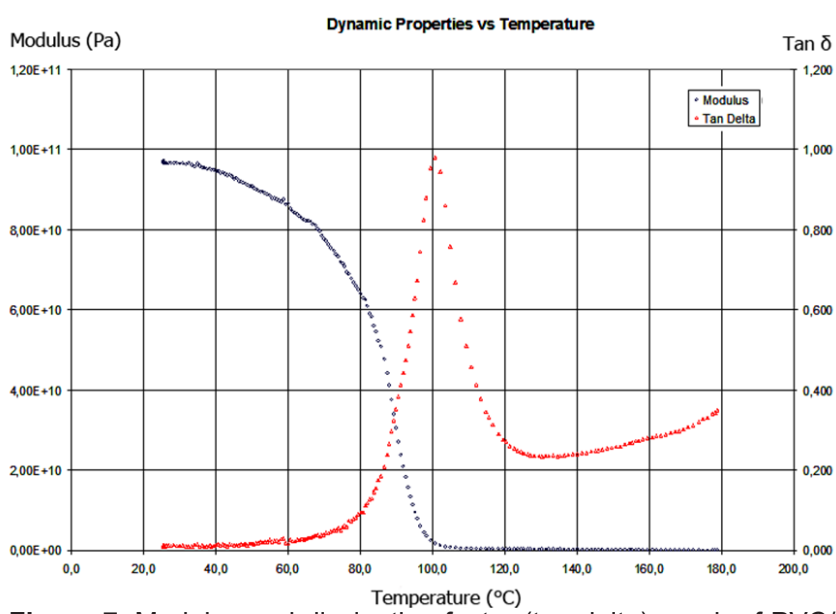

Figure 7. Modulus and dissipation factor (tan delta) graph of PVC/ nZB2335-5 between $30-180^{\circ} \mathrm{C}$.

Tg values of the PVC/nZB411-5 composite were detected as $75^{\circ} \mathrm{C}$ and $100^{\circ} \mathrm{C}$ according to modulus curve and tan $\delta$ curve, respectively. The Tg values obtained from the tan $\delta$ for PVC-ZB composites and PVC did not have a significant difference. PVC/nZB411-5 composite with $5 \%$ ratio caused a slight decrease in glassy transition temperature. The starting modulus value of the PVC/nZB411-5 composite was $10 \times 10^{10} \mathrm{~Pa}$ (Figure $8)$. This value was found to be higher than the starting modulus of PVC which had a modulus value of $7 \times 10^{6}$ at $30^{\circ} \mathrm{C}$ as starting temperature.

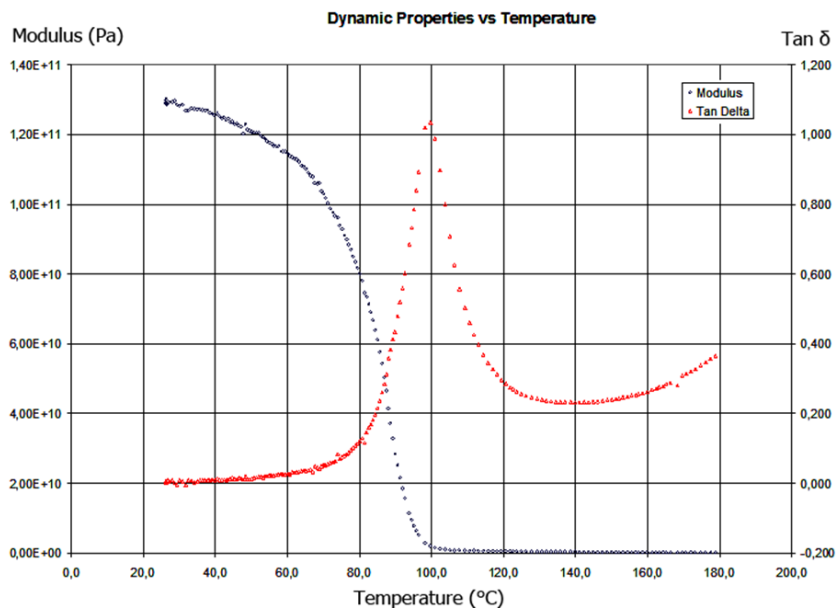

Figure 8. Three dimensional AFM view of $5 \mu \mathrm{m} \times 5 \mu \mathrm{m}$ are of worn surfaces of balls after four ball tests. Surfaces of ball tested with a. Spindle oil, b. Spindle oil with Span 60 c. Spindle oil with Span 60 and zinc borate heated for 15 hours. 
Tg and initial modulus values (E') of PVC and PVC-ZB composites are given in Table 5 as a summary. The initial modulus at $30^{\circ} \mathrm{C}$ increased significantly with the addition of zinc borate to the PVC structure and the $\mathrm{Tg}$ values were decreased. The presence of single peak in the $\tan \delta$ curves corresponded to the single type polymer composition [33, 34]. The higher difference between $\mathrm{Tg}$ values according to E' curve and tan $\delta$ curve, signifies less molecular mobility [35]. Lower mobility means that the polymer has more flexible backbone polymer chains. According to the data in Table 5, PVC/nZB411 composites had lowest molecular or chain mobility. Agglomeration of nanoparticles caused an increase of free volume and $\mathrm{Tg}$ value of the composites decreased [36].

Table 5. Tg and initial modulus values (E') of PVC and PVC-ZB composites.

\begin{tabular}{lccc}
\multicolumn{1}{c}{ Sample } & $\left.\begin{array}{c}\mathbf{T g ~ ( E}^{\prime} \\
\text { curve, }\end{array}{ }^{\circ} \mathbf{C}\right)$ & $\begin{array}{c}\mathbf{T g}^{(\tan \delta} \\
\left.\text { curve, }{ }^{\circ} \mathbf{C}\right)\end{array}$ & $\begin{array}{c}\text { Modulus } \\
\text { at } 30^{\circ} \mathbf{C}(\mathbf{P a})\end{array}$ \\
\hline PVC & 82 & 102 & $7.3 \times 10^{6}$ \\
PVC/nZB411-1 & 75 & 100 & $8.2 \times 10^{10}$ \\
PVC/nZB411-5 & 75 & 100 & $13 \times 10^{10}$ \\
PVC/nZB2335-1 & 81 & 100 & $5.8 \times 10^{10}$ \\
PVC/nZB2335-5 & 80 & 100 & $9.7 \times 10^{10}$ \\
PVC/mZB2335-1 & 77 & 100 & $8.6 \times 10^{10}$ \\
PVC/mZB2335-5 & 80 & 101 & $12.5 \times 10^{10}$ \\
\hline
\end{tabular}

\section{Conclusions}

Although it has a high fire resistance, adding flame retardant and smoke suppressant zinc borate to PVC is an important process to reduce the loss of life in fires due to the toxicity of the gases released as a result of combustion. In the present study, the investigation of the effect of zinc borate additive on the mechanical properties of PVC has provided an idea on the limits of the use of zinc borate in PVC products. Tensile strength, impact resistance, hardness and dynamic mechanical properties were examined and scanning electron microscope images of the materials were obtained after mechanical tests. Although zinc borate additive did not lead any change in the physical appearance and hardness of PVC, it was observed that nano or micro-sized zinc borate particles agglomerated during composite preparation process. In the perspective of influencing mechanical properties, additive ratio of $Z B$ was more effective than particle size and chemical formulation of ZB. In the aspect of flame retardancy, other researchers, who studied on PVC-ZB composites, applied the concentration of flame retardant in the range of $1 \%$ to $5 \%[25,26,27]$. For a desired mechanical strength, the doping ratio more than $5 \%$ by weight can negatively affect the mechanical strength and quality of the PVC-ZB composite. Poor interface compatibility between ZB and PVC and agglomeration of nano-sized particles were determined as the main reasons for the weakening of mechanical strength. As a solution suggestion, surface active agents such as PEG 300 [37] or oleic acid [38, 39] can be utilized in the synthesis process of $\mathrm{ZB}$ to prevent the agglomeration and improve the interaction of PVC and ZB interfaces.

\section{Symbols}

w/w : Weight/weight ratio

$\mathrm{Tg}$ : Glass transition temperature

E' : Modulus value

\section{Acknowledgement}

Great thanks to TENMAK-Boron Research Institute (BOREN) (Project No: 2008-C0154) for financial support.

\section{References}

1. Karama, J.P.B., Béré, A., Lemonon, J., Daho, T., Dissa, A., Rogaume, Y. \& Koulidiati, J. (2013). Modeling the emission of hydrogen chloride and free chlorine from the thermal treatment of polyvinyl chloride (PVC) based plastic materials. Journal of Analytical and Applied Pyrolysis, 101, 209-214,

2. Bockhorn, H., Hornung, A. \& Hornung, U. (1998). Stepwise pyrolysis for raw material recovery from plastic waste. Journal of Analytical and Applied Pyrolysis, 46, $1-13$.

3. Zhang, M., Buekens, A., Jiang, X. \& Li, X. (2015). Dioxins and polyvinylchloride in combustion and fires. Waste Management \& Research, 33(7), 630-643.

4. Calò, E., Greco, A., Maffezzoli, A. (2011). Effects of diffusion of a naturally-derived plasticizer from soft PVC. Polymer Degradation and Stability, 96(5) 784-789.

5. Nakamura, S., Nakajima, K., Yoshizawa, Y., MatsubaeYokoyama, K., Nagasak T. (2009). Analyzing polyvinyl chloridein japan with the waste input-output material flow analysis model. Research and Analysis, 13(5), 706-718.

6. Polat, S., \& Sayan, P. (2020). Box-behnken experimental design for zinc borate $\mathrm{Zn} 2 \mathrm{~B} 6 \mathrm{O} 11 \cdot 7 \mathrm{H} 2 \mathrm{O}$. Journal of Boron, 5(3), 152-161.

7. Cusack, P. A., \& Killmeyer, A. J. (1990). Hazards Identifications Prevention: Fire and Polymers, Nelson G.L. (Ed.), American Chemical Society, Washington, DC, p. 199.

8. Schubert, D. M. (2019). Hydrated Zinc Borates and Their Industrial Use. Molecules, 24(13), 2419.

9. Ijpek, Y., \& Ertekin, Ö. (2021). Developing antibacterial cotton fabric with zinc borate impregnation process. Fibers and Polymers, 22(5), 2826-2833.

10. Çakal, G. Ö., Baltacı, B., Bayram, G., Özkar, S., \& Eroglu, I. (2020). Synthesis of zinc borate using water soluble additives: Kinetics and product characterization. Journal of Crystal Growth, 533, 125461.

11. Ata, O. N., Şayan, E., \& Engin, B. (2011). Optimization and modeling of zinc borate $(2 \mathrm{ZnO} \cdot 3 \mathrm{~B} 2 \mathrm{O} 3 \cdot 3.5 \mathrm{H} 2 \mathrm{O})$ production with the reaction of boric acid and zinc oxide. Journal of Industrial and Engineering Chemistry, 17(3), 493-497.

12. Shen, K. K., Kochesfahani, S. \& Jouffret, F. (2008). 
Zinc borates as multifunctional polymer additives. Polymers for Advanced Technologies, 19, 469-474.

13. Wang, X., Li, L., Tong, Y., Dai, Y., \& Chen, W. (2021). Synthesis of core/shell structured zinc borate/silica and Its surface charring for enhanced flame retardant properties. Polymer Degradation and Stability, 183, 109432

14. Fang, Y., Wang Q., Guo C., Song Y., \& Cooper P. A. (2013). Effect of zinc borate and wood flour on thermal degradation and fire retardancy of polyvinyl chloride (PVC) composites. Journal of Analytical and Applied Pyrolysis, 100, 230-236.

15. Giudice, C. A., \& Benitez, J. C. (2001). Zinc borates as flame-retardant pigments in chlorine-containing coating. Progress in Organic Coatings, 42(1/2), 82-88.

16. Meinier, R., Sonnier, R., Zavaleta, P., Suard, S., \& Ferry L. (2018). Fire behavior of halogen-free flame retardant electrical cables with the cone calorimeter. Journal of Hazardous Materials, 342, 306-316.

17. Dogan, M., Dilem Dogan, S., Atabek Savas, L., Ozcelik, G., \& Tayfun, U. (2021). Flame retardant effect of boron compounds in polymeric materials. Composites Part B: Engineering, 222, 109088.

18. Araby, S., Philips, B., Meng, Q., Ma, J., Laoui, T., \& Wang, C. H. (2021). Recent advances in carbon-based nanomaterials for flame retardant polymers and composites. Composites Part B: Engineering, 212, 108675.

19. Liu, P., Chen, W., Liu, Y., Bai, S., \& Wang, Q. (2014). Thermal melt processing to prepare halogen-free flame retardant poly(vinyl alcohol). Polymer Degradation and Stability, 109, 261-269.

20. Pi, H., Guo, S., \& Ning Y. (2003). Mechanochemical improvement of the flame-retardant and mechanical properties of zinc borate and zinc borate-aluminum trihydrate-filled poly(vinyl chloride). Journal of Applied Polymer Science, 89, 753-762.

21. Zhang, Z., Wu, W., Zhang, M., Qu, J., Shi, L., Qu, H., \& Xu, J. (2017). Hydrothermal synthesis of $4 \mathrm{ZnO} \cdot \mathrm{B} 2 \mathrm{O} 3 \cdot \mathrm{H} 2 \mathrm{O} / \mathrm{RGO}$ hybrid material and its flame retardant behavior in flexible PVC and magnesium hydroxide composites. Applied Surface Science, 425, 896-904.

22. Demirel, M., Pamuk, V., \& Dilsiz, N. (2009). Investigation of flame retardancy and physical-mechanical properties of zinc borate/boric acid polyester composites. Journal of Applied Polymer Science, 115(5), $2550-2555$

23. Erdoğdu, C. A., Atakul, S., Balköse D., \& Ülkü S. (2008). Development of synergistic heat stabilizers for PVC from zinc borate-zinc phosphate. Chemical Engineering Communications, 196(1-2), 148-160.

24. Jian, R. K., Lin, X. B., Liu, Z. Q., Zhang, W., Zhang, J., Zhang, L., Li, Z., \& Wang, D. Y. (2020). Rationally designed zinc borate@ZIF-8 core-shell nanorods for curing epoxy resins along with low flammability and high mechanical property. Composites Part B: Engineering, 200,108349
25. Mergen, A., İpek, Y., Bölek, H., \& Öksüz, M. (2012). Production of nano zinc borate $(4 \mathrm{ZnO} \cdot \mathrm{B} 2 \mathrm{O} 3 \cdot \mathrm{H} 2 \mathrm{O})$ and its effect on PVC. Journal of the European Ceramic Society, 32, 2001-2005.

26. Thomas, N. L. (2003). Zinc compounds as flame retardants and smoke suppressants for rigid PVC. Plastics, Rubber and Composites, 32(8-9), 413-419.

27. Ning, Y., \& Guo, S. (2000). Flame-retardant and smoke-suppressant properties of zinc borate and aluminum trihydrate-filled rigid PVC. Journal of Applied Polymer Science, 77, 3119-3127.

28. Borukaev, T. A., Shaov, A. K., Kharaev, A. M., \& Borodulin, A. S. (2020). Investigation of the effect of zinc borate on the physic mechanical properties of PVC plastic. Materials Science and Engineering, 934, 012001.

29. Ismail, A. F., Khulbe, K. C., \& Matsuura, T. (2019). Chapter 3 - RO Membrane Characterization, Editor(s): Ahmad Fauzi Ismail, Kailash Chandra Khulbe, Takeshi Matsuura, Reverse Osmosis, Elsevier, 57-90, ISBN 9780128114681.

30. Çetin, A., Erzengin, S. G., \& Alp, F. B. (2019). Various combinations of flame retardants for poly(vinyl chloride). Open Chemistry, 17, 980-987.

31. Kilinc, M., Cakal, G. O., Bayram, G., Eroglu, I., \& Özkar, S. (2015). Flame retardancy and mechanical properties of pet-based composites containing phosphorus and boron-based additives. Journal of Applied Polymer Science, 132(22), 42016.

32. Yerleşen, U., \& Taşdemir, M. (2015). Effect of zinc oxide and zinc borate on mechanical properties of high density polyethylene. Romanian Journal of Materials, 45(3), 240-243.

33. George, S., Neelakantan, N. R., Varughese, K. T., \& Thomas, S. (1997). Dynamic mechanical properties of isotactic polypropylene/nitrile rubber blends: effects of blend ratio, reactive compatibilization, and dynamic vulcanization. Journal of Polymer Science Part B. Polymer Physics, 35(14), 2309-2327.

34. Varughese, K. T., Nando, G. B., De, P. P., \& De, S. K. (1988). Miscible blends from rigid poly (vinyl chloride) and epoxidized natural rubber. Journal of Materials Science, 23(11), 3894-3902.

35. Perera, M. S., Ishiaku, U. S., \& Ishak, Z. M. (2001). Characterisation of PVC/NBR and PVC/ENR50 binary blends and PVC/ENR50/NBR ternary blends by DMA and solid state NMR. European Polymer Journal, $37(1), 167-178$.

36. Goswami, S., Ghosh, R., Neog, A., \& Das, B. (2021). Deep learning based approach for prediction of glass transition temperature in polymers, Materials Today: Proceedings, 46(12), 5838-5843.

37. Shi, X., Yuan, L., Sun, X., Chang, C., \& Sun, J. (2008). Controllable synthesis of $4 \mathrm{ZnO} \cdot \mathrm{B} 2 \mathrm{O} 3 \cdot \mathrm{H} 2 \mathrm{O}$ nano/microstructures with different morphologies: Influence of hydrothermal reaction parameters and formation mechanism. The Journal of Physical Chemistry C, 112(10), 3558-3567. 
38. Ipek, Y. (2020). Effect of surfactant types on particle size and morphology of flame-retardant zinc borate powder. Turkish Journal of Chemistry, 44, 214-223.
39. Li, S., Long, B., Wang, Z., Tian, Y., Zheng, Y., \& Zhang, Q. (2010). Synthesis of hydrophobic zinc borate nanoflakes and its effect on flame retardant properties of polyethylene. Journal of Solid State Chemistry, 183(4), 957-962. 